\title{
Knowledge, Attitude and Practice of Emergency Contraceptives among Mizan-Tepi University Female Students, South West Ethiopia
}

\section{Bisrat Zeleke Shiferaw ${ }^{*}$, Bosena Tebeje Gashaw ${ }^{2}$ and Fekadu Yadassa Tesso ${ }^{2}$}

${ }^{1}$ Department of Nursing, Wolkite University, College of Medicine and Health Sciences, PO Box 07 Wolkite, Ethiopia

${ }^{2}$ Department of Nursing and Midwifery, Jimma University College of Public Health and Medical Sciences, PO Box 1355 Jimma, Ethiopia

\begin{abstract}
Background: Emergency contraception is a type of modern contraception which is used after unprotected sexual intercourse, following sexual abuse, misuse of regular contraception or non-use of contraception. University students fall under sexually active age group and form a high-risk group for unintended pregnancy because a large percentage of them engage in sporadic pre- marital sex, which could be prevented by using emergency contraception.
\end{abstract}

Objective: The aim of the study was to assess the knowledge, attitude and practice of emergency contraceptives among female students in Mizan-Tepi University, South West Ethiopia. Methods: For the study, a cross-sectional, Institution based study was conducted from March 10-30, 2014. A multistage sampling technique was used to select the study participants. Data were cleaned, coded and entered in to Epi-data 3.1 and analyzed using SPSS version 20:-00. Logistic regression was used to identify the association between variables and emergency contraceptive knowledge, attitude and practice.

Result: Of the total, respondents, $188(38.4 \%)$ of them were sexually active, only $24.1 \%$ had good knowledge about emergency contraceptives, $229(46.8 \%)$ of the students had favorable attitude towards it and among sexually active participants, only $68(36.2 \%)$ had used emergency contraceptive methods.

Conclusion: The study shows lack of awareness, knowledge and utilization of emergency contraceptives among Mizan-Tepi University female students. Therefore, designing specific strategies to enhance emergency contraceptive utilization by increasing female students' level of awareness on emergency contraceptive is recommended.

Keywords: Emergency contraceptives; Knowledge; Attitude; Practice; Mizan-Tepi University

Abbreviations: EC: Emergency Contraception; ECPs: Emergency Contraceptive Pills; ERB: Ethical Review Board; IUCD: Intra Uterine Contraceptive Device; KAP: Knowledge, Attitude, and Practice; MTU: Mizan-Tepi University; SPSS: Statistical Package for Social Science

\section{Introduction}

Emergency contraception (EC) also called: "post coital contraception", or "second chance" is a type of modern contraception which is used after unprotected sexual intercourse, following sexual abuse, misuse of regular contraception or non-use of contraception [1]. If used correctly, all types of emergency contraceptive pills (ECPs) can decrease the risk of unintended pregnancy by more than $75 \%$ which in turn helps to reduce unintended pregnancy and unsafe abortion [2].

Globally, there are about 210 Million pregnancies each year, some 80 million of these are unintended, and one in ten of these pregnancies end in an unsafe abortion. An estimated 529,000 girls and women die from pregnancy-related causes each year worldwide, of which $13 \%$ are due to unsafe abortion. It's estimated that two in five unsafe abortions occur among women under age 25 and about one in seven women who have unsafe abortions are under $20[3,4]$.

In developing world, about $56 \%$ of all abortions are unsafe compared to the developed world (6\%) and nearly all unsafe abortions (98\%) occur in developing countries [4]. In Africa, among the annual number of induced abortions (6.4 million), only 3\% are performed under safe conditions. Eastern African countries contributed nearly $39.1 \%$ (2.5 million) of all induced abortions occurred in Africa in 2008, a higher proportion than in any other regions of the continent [5]. Ethiopia is one of the countries with high maternal mortality rate (676 per 100,000 live births), which is responsible for $30 \%$ of all deaths to women of age
15-49. It is estimated that $34 \%$ of all women are either mothers or are pregnant with their first child by age 19 [6].

University students fall under sexually active age group and form a high-risk group for unintended pregnancy because a large percentage of them engage in sporadic pre-marital sex, which could be prevented by using EC [7]. In Ethiopia, most of university students travel far from their home for higher education studies, and they are out of care and protection of their parents and families, which makes them more vulnerable to unprotected and accidental sex which leads to unintended pregnancy.

Unintended pregnancy either ends with unsafe abortion or early child bearing; it has a negative impact on the educational progress, future careers and even social interaction of female students by forcing them to drop out of school. On the other hand, this segment of the population is tomorrow's generation in pipeline to take over the responsibilities of socioeconomic development of the country. Thus, they should be protected from unintended pregnancy that could have been considerably prevented by emergency contraception [8-11].

Studies conducted in different African countries higher institutions

*Corresponding author: Bisrat Zeleke Shiferaw, Department of Nursing, Wolkite University, College of Medicine and Health Sciences, PO Box 07 Wolkite, Ethiopia, Tel: +251911037686; E-mail: basfendaz@gmail.com

Received January 27, 2016; Accepted February 08, 2016; Published February 12, 2016

Citation: Shiferaw BZ, Gashaw BT, Tesso FY (2016) Knowledge, Attitude and Practice of Emergency Contraceptives among Mizan-Tepi University Female Students, South West Ethiopia. J Pain Manage Med 2: 111.

Copyright: (c) 2016 Shiferaw BZ, et al. This is an open-access article distributed under the terms of the Creative Commons Attribution License, which permits unrestricted use, distribution, and reproduction in any medium, provided the original author and source are credited. 
have shown that level of knowledge and practices of EC among higher level institution female students is limited [12-15]. In one of the studies conducted among 417 women of post abortion care clients in Ethiopia, $59(14.1 \%)$ had ever heard of EC, and only $15(8.6 \%)$ had ever used EC [16]. In another study among 833 college students in one of the towns of Ethiopia, the magnitude of sexual violence was $47.9 \%$, and unwanted pregnancy was found to be $16.9 \%$; about $228(27.4 \%)$ had knowledge about EC, 20(2.4\%) had ever used it and about 548(65.8\%) had favorable attitude towards use of EC [17].

As there are no studies in this problem in the study area, this study was conducted to assess knowledge, attitude and practice of emergency contraceptives among female students of Mizan-Tepi University and to further elucidate the relationship between Knowledge Attitude and Practice (KAP) of EC with socio-demographic sexual and reproductive characteristics.

\section{Methods and Materials}

An institution based cross sectional study was conducted on regular program female students of Mizan-Tepi University (MTU) from March 10 to 30, 2014 with the objective of assessing knowledge, attitude and practice of emergency contraceptives. MTU is located $561 \mathrm{~km}$ away from the capital city of the country (Addis Ababa) to the south-west of Ethiopia. It is among the emerging 13 new universities established in the country in the last decades. According to the registrar office of the University, MTU has a total of 34 departments under 6 colleges and in the academic year 2013-14, a total of 8652 students were registered, among which 6174 were in regular program and 1988 were females.

The sample size was calculated using a single population proportion formula with confidence interval of $95 \%$ and margin of error $5 \%$. In the calculation, the prevalence of EC among sexually active female students was considered to be $24.2 \%$ [18]. Then, because the source population $(\mathrm{N})$ is less than 10,000 using the finite population correction formula, the sample size was recalculated and along with $10 \%$ non-response rate and considering the design effect of 2, the final sample size was 540 .

A multistage sampling technique method was used; where first, 17 departments were selected from the 34 departments using lottery method. Then, the total sample size was allocated to each department proportional to the number of female students in the department. Secondly, participant students were selected from each department proportional to their year of study using simple random sampling technique. Finally, the study units were selected from each department using simple random sampling technique considering the list of female students as a sample frame.

The data were collected using pre-tested, structured selfadministered questionnaires which developed from different literatures and adapted to the local situations. It was prepared in English and translated in to Amharic and back retranslated to English to check its consistency. The instrument was tested for reliability and validity and accordingly, the cronbach alpha coefficient was found to be 0.84 .

Female students' knowledge about EC was measured using eight multiple-choice items. Each correct answer awarded one point, and so there were a total of 8 points for the eight items. For questions that consist of more than one correct answer, respondents who have identified at least one possible response were given one point. Based on their cumulative result, those respondents who scored above four out of eight knowledge assessing items were assigned as having "good knowledge" on EC and those who scored four and below were regarded as having "poor knowledge".
Students' attitude towards EC was assessed using eight items rated on a five-point Likert scale as (1) strongly agree, (2) agree, (3) not sure , (4) disagree and (5) strongly disagree. For the purpose of ease of analysis, attitude of female students towards the utilization of EC items were condensed into three categories as "agree", "disagree" and "not sure". Furthermore, the attitude measurement Likert scale was summarized as "favorable attitude" (those who scored above the mean on attitude items), and "unfavorable attitude" (those who scored the mean or below mean to attitude measuring items).

The questionnaire was distributed to the students by five Graduate Assistants working in Mizan Aman Health Sciences College, and the data were collected while students were in class rooms and the instructors cooperated with data facilitators in disseminating the questionnaire. On completion, the questionnaires were placed in sealed boxes by the participants.

The collected data was cleaned, coded and entered into Epi-data 3.1 software, and then exported to Statistical Package for Social Sciences (SPSS) version 20:00 for analysis. Logistic regression analysis was used to evaluate the association between different variables and knowledge, attitude and practice of participants about EC. P-value less than 0.05 at 95\% CI was taken for statistical significance.

Before conducting the study, it was submitted to Jimma University and letter of ethical clearance approval was obtained from Jimma University, College of Public Health and Medical Sciences, Ethical Review Board (ERB). The purpose of the study was explained to the study participants and privacy and confidentiality was ensured. Prior to data collection, informed verbal consent was obtained from the study participants. For three of the study participants whose age was 17 years and involved in the quantitative study, parental informed consent was obtained. The respondents' right to refuse or withdraw from participating in the study was fully acknowledged.

\section{Result}

A total of 489 students completed the questionnaire making a response rate of $90.6 \%$. Age of study participants ranged from 17-31 years with mean of $20.7 \pm 1.7$ years. More than half $(51.5 \%)$ of the respondents were followers of the Orthodox Christianity followed by protestant and Muslim which accounted for 141 (28.8\%) and 67 (13.7\%) respectively. Four hundred and forty eight (91.6\%) of the respondents were single (Table 1).

From the total study participants about 188 (38.4\%) of the respondents were sexually active, of these 81 (43.1\%) students had an experience of pregnancy at least once and majority, 69 (85.2\%) of the pregnancies were unwanted (Table 2).

Of the total participants, 332(67.8\%), ever heard about EC; the sources of information were mass media $158(47.6 \%)$, peers/friends 85(25.6\%), schools club 49(14.7\%), and health workers $40(12.1 \%)$ (Figure 1). Among female students who heard about EC 332(67.8\%), only $94(28.3 \%)$ correctly identified time of administration of the method, $54(16.3 \%)$ the recommended doses, and $49(14.8 \%)$ the recommended number of doses and the time interval between the doses. Furthermore, the knowledge summary index about EC also shows that the majority, $238(71.7 \%)$ of the respondents had poor knowledge on EC (Table 3 ).

With regard to attitudes towards EC, about half of the respondents $246(50.3 \%)$ believes that EC may cause infertility in a woman and more than half $253(51.7 \%)$ of the participants believes that emergency contraception may hurt the baby in case it does not work. Concerning the overall level of female students' attitudes, more than half (53.2\%) of 
Citation: Shiferaw BZ, Gashaw BT, Tesso FY (2016) Knowledge, Attitude and Practice of Emergency Contraceptives among Mizan-Tepi University Female Students, South West Ethiopia. J Pain Manage Med 2: 111.

\begin{tabular}{|c|c|c|}
\hline Variables & Number & Percent \\
\hline \multicolumn{3}{|l|}{ Age category } \\
\hline $15-19$ & 154 & 31.5 \\
\hline $20-24$ & 323 & 66.1 \\
\hline $25-29$ & 9 & 1.8 \\
\hline$\geq 30$ & 3 & 0.6 \\
\hline \multicolumn{3}{|l|}{ Year of study } \\
\hline First year & 134 & 27.4 \\
\hline Second year & 126 & 25.8 \\
\hline Third year & 169 & 34.6 \\
\hline Fourth year & 52 & 10.6 \\
\hline Fifth year & 8 & 1.6 \\
\hline \multicolumn{3}{|l|}{ Field of study } \\
\hline None health sciences & 431 & 88.1 \\
\hline Health sciences & 58 & 11.9 \\
\hline \multicolumn{3}{|l|}{ Marital status } \\
\hline Single & 448 & 91.6 \\
\hline Married & 38 & 7.8 \\
\hline Divorced & 3 & 0.6 \\
\hline \multicolumn{3}{|l|}{ Religion } \\
\hline Orthodox & 250 & 51.2 \\
\hline Protestant & 141 & 28.8 \\
\hline Muslim & 67 & 13.7 \\
\hline Catholic & 21 & 4.3 \\
\hline Others $^{a}$ & 10 & 2.0 \\
\hline \multicolumn{3}{|l|}{ Ethnicity } \\
\hline Amhara & 193 & 39.5 \\
\hline Oromo & 174 & 35.6 \\
\hline Tigrie & 46 & 9.4 \\
\hline Wolita & 29 & 5.9 \\
\hline Gurage & 25 & 5.1 \\
\hline Others $^{b}$ & 22 & 4.5 \\
\hline
\end{tabular}

aOther ethnic group refers to Keffa, Dawro, Silte, Sidama and Bench; ' $O$ ther religious group refers to Adventist and Jehovah

Table 1: Socio-Demographic Characteristics of Female Students, Mizan-Tepi University, south west Ethiopia, March, 2014 ( $n=489)$.

\begin{tabular}{|c|c|c|}
\hline Variables & Number & Percen \\
\hline \multicolumn{3}{|c|}{ Ever had sex since in the campus $(n=489)$} \\
\hline Yes & 188 & 38.4 \\
\hline No & 301 & 61.6 \\
\hline \multicolumn{3}{|c|}{ Age at first sex $(n=188)$} \\
\hline $15-19$ & 122 & 64.8 \\
\hline$\geq 20$ & 66 & 35.1 \\
\hline \multicolumn{3}{|c|}{ Unprotected sex $(n=188)$} \\
\hline Yes & 123 & 65.4 \\
\hline No & 65 & 34.6 \\
\hline \multicolumn{3}{|c|}{ History of Pregnancy $(n=188)$} \\
\hline Yes & 81 & 43.1 \\
\hline No & 107 & 56.9 \\
\hline \multicolumn{3}{|c|}{ Unintended pregnancy $(n=81)$} \\
\hline Yes & 69 & 85.2 \\
\hline No & 12 & 14.8 \\
\hline
\end{tabular}

Table 2: Sexual and Reproductive History of Female Students, Mizan-Tepi University, South west Ethiopia, March, 2014.

them had unfavorable attitude towards EC (Table 4).

Regarding the utilization of EC, among those who are sexually active, only 68(36.2\%) had ever used EC and it was 57(46.3\%) among those who had unprotected sex. Emergency contraceptive pills were the commonest EC method used majorly which accounted for $97.1 \%$ (Table 5).

Bivariate and multiple logistic regression analyses were done to determine the association between dependent variables and EC Knowledge, attitude and practice. After adjusting for other variables the multivariate analysis shows that, Students of age 20 and above were more likely to have good knowledge about EC than their counter parts (under 20 years) $[\mathrm{AOR}=2.3 ; 95 \% \mathrm{CI}$ : $1.102,4.25]$. Likewise, as the year of study in campus increases, their knowledge about emergency contraceptive appears to be increase [AOR=2.4; 95\%CI: 1.12, 3.83] for year two and above. Female students who had sexual intercourse were found 4.9 times more likely to be aware of EC than their counter parts [AOR=4.9; $95 \%$ CI: $2.68,9.65]$. Similarly female students who had history of pregnancy and had ever used regular contraceptives were found 4.4 and 5 times more likely to be knowledgeable than their counterparts respectively with respective adjusted odd ratio of $[\mathrm{AOR}=4.4 ; 95 \% \mathrm{CI}$ : $6.00,9.88$ ] and [AOR=5.0; 95\% CI: 5.23, 14.27] (Table 6).

After adjusting for other variables, favorable attitude towards EC was significantly higher among Students of age 20 and above than their counter parts [AOR=1.8; 95\% CI: 2.2, 4.96]. Favorable attitude towards emergency contraceptives was also higher among ever married respondents' and respondents who had history of pregnancy, with an adjusted odd ratio of $[\mathrm{AOR}=1.1 ; 95 \% \mathrm{CI}: 0.67,2.26]$ and $[\mathrm{AOR}=3.5$; 95\%CI: $2.03,7.97]$ respectively. The likelihood of favorable attitude towards EC among those female students who had sexual intercourse was 4.8 times higher than their counter parts [AOR $=4.8$; 95\%CI: 3.80, 7.45] (Table 6).

With regard to practice of EC among sexually active female students $(n=188)$, the multivariate logistic regression analysis shows that female students who had first sexual intercourse at age 20 and above were 4 times more likely to use EC as compared to those who had their first sexual intercourse at younger age (15-19 years), [AOR: 4.048; 95\% $\mathrm{CI}=1.721,9.524]$. Respondents who had history of pregnancy were 3 times more likely to use EC than those with no exposure of pregnancy [AOR: 3.122; 95\% CI=1.346, 7.240]. Similarly, students who had good knowledge on EC were 3.2 times more likely to use EC than those female students who were not knowledgeable about EC [AOR: 3.248; $95 \% \mathrm{CI}=1.320,7.988]$. The result also showed that respondents who had experience of other forms of regular contraceptive use were 5 times more likely to use EC than those who didn't use other forms of regular contraceptives [AOR: 5.019; 95\% CI=2.234, 11.274] (Table 7).

\section{Discussion}

In this study about 188 (38.4\%) of the subjects reported that they are already sexually active. This result is nearly similar to the study conducted on South Africa Secondary School female students and Nigerian female undergraduates' students $[19,20]$. The result is also higher than similar study conducted on higher education students in Adama, Assella and Addis Ababa, [8,17,21]. In this study about $81(43.1 \%)$ of ever sexually active respondents gave history of at least one pregnancy, of which $85.2 \%$ were unwanted pregnancies. But, the prevalence of unwanted pregnancy among the total study participants was $14.1 \%$, which is lower than reported by other study conducted among higher education female students in Addis Ababa [21].

Though more than half of the respondents have heard about EC in this study, only $94(28.3 \%)$ of them had identified the correct timing of administration of the pills after unexpected sexual contact. Several 
Citation: Shiferaw BZ, Gashaw BT, Tesso FY (2016) Knowledge, Attitude and Practice of Emergency Contraceptives among Mizan-Tepi University Female Students, South West Ethiopia. J Pain Manage Med 2: 111.

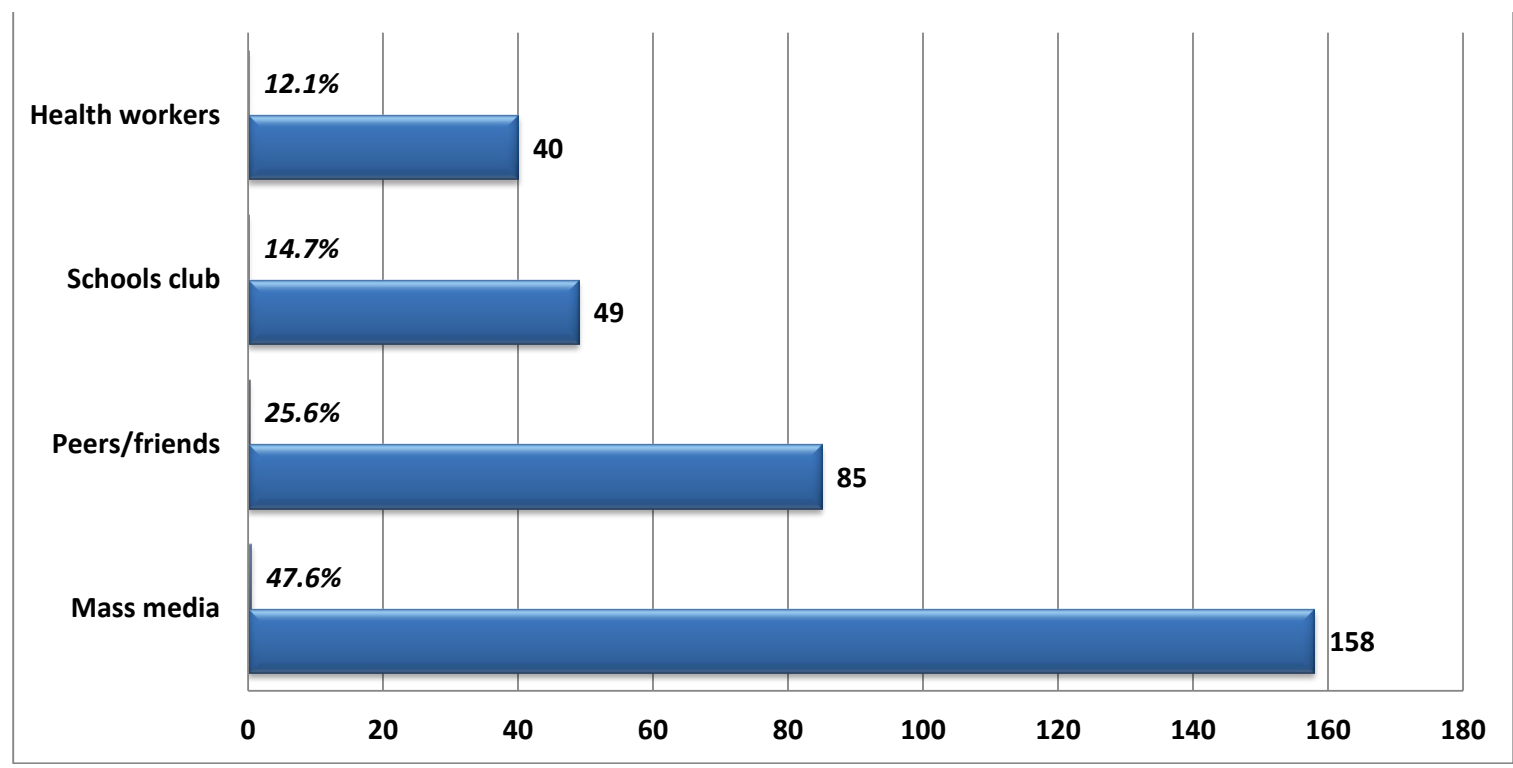

Figure 1: Source of Information about Emergency contraceptive among participants ever heard about Emergency contraceptive, Mizan-Tepi University, South west Ethiopia, March, $2014(n=332)$.

\begin{tabular}{|c|c|c|}
\hline Knowledge assessment items & Number & Percent \\
\hline \multicolumn{3}{|c|}{ Where do you think emergency contraception could be obtained } \\
\hline Pharmacy/Health facility & 87 & 26.2 \\
\hline Any shops & 143 & 43.1 \\
\hline I don't know & 102 & 30.7 \\
\hline \multicolumn{3}{|c|}{ Which one of these drugs can be used for emergency contraception } \\
\hline Combined oral contraceptive & 98 & 29.5 \\
\hline Progesterone only pills and IUCD & 90 & 27.1 \\
\hline Anti-biotic like ampicillin & 34 & 10.2 \\
\hline I don't know & 110 & 33.2 \\
\hline \multicolumn{3}{|c|}{ When taken early, emergency contraception prevent sexually transmitted infections } \\
\hline Yes & 158 & 47.5 \\
\hline No & 51 & 15.4 \\
\hline I don't know & 123 & 37.1 \\
\hline \multicolumn{3}{|c|}{ Situation(s) that emergency contraception should be taken } \\
\hline If condom ruptured during intercourse & 109 & 32.8 \\
\hline When there is a missed pill & 78 & 23.4 \\
\hline When forced to have sex/rape & 140 & 42.1 \\
\hline When there is failure of contraception & 169 & 50.9 \\
\hline I don't know & 145 & 43.6 \\
\hline \multicolumn{3}{|c|}{ The recommended maximum time limit to take emergency contraception Pills } \\
\hline Within 24 hours after sex & 120 & 36.1 \\
\hline Within 72 hours after sex & 94 & 28.3 \\
\hline Within 5 days after sex & 42 & 12.7 \\
\hline I don't know & 76 & 22.9 \\
\hline \multicolumn{3}{|c|}{ Effectiveness of emergency contraception Pills in preventing pregnancy } \\
\hline Highly effective (>95\%) & 52 & 15.7 \\
\hline Effective $(75-89 \%)$ & 68 & 20.5 \\
\hline Less effective $(<10 \%)$ & 29 & 8.7 \\
\hline Not effective at all & 40 & 12.0 \\
\hline I don't know & 143 & 43.1 \\
\hline \multicolumn{3}{|c|}{ Recommended number of dose of emergency contraception Pills } \\
\hline One dose & 50 & 15.1 \\
\hline Two doses & 54 & 16.3 \\
\hline Three doses & 35 & 10.5 \\
\hline I don't know & 193 & 58.1 \\
\hline
\end{tabular}


Citation: Shiferaw BZ, Gashaw BT, Tesso FY (2016) Knowledge, Attitude and Practice of Emergency Contraceptives among Mizan-Tepi University Female Students, South West Ethiopia. J Pain Manage Med 2: 111.

Page 5 of 7

\begin{tabular}{|c|c|c|}
\hline \multicolumn{3}{|c|}{ Recommended time between the doses of emergency contraception Pills } \\
\hline Twelve hours apart & 49 & 14.8 \\
\hline Twenty-four hours apart & 45 & 13.5 \\
\hline Seventy- two hours apart & 50 & 15.1 \\
\hline I don't know & 188 & 56.6 \\
\hline \multicolumn{3}{|c|}{ Knowledge of EC (Summary index) } \\
\hline Good knowledge & 80 & 24.1 \\
\hline Poor knowledge & 252 & 75.9 \\
\hline
\end{tabular}

Table 3: Knowledge about Emergency Contraception among Female Students, Mizan-Tepi University, south west Ethiopia, March, 2014 ( $n=332$ ).

\section{Attitude Assessment Items}

Provision of Emergency contraception after an episode of un-protected sex can prevent unwanted pregnancy

All females have the right to access emergency contraception

Emergency contraception promotes promiscuity

Emergency contraception may hurt the baby in case it does not work

Emergency contraception is one way of abortion

It is sinful act to use emergency contraception

Emergency contraception use may cause infertility in a woman

Emergency contraception will affect ongoing regular methods of contraception negatively

Attitude of EC (Summary index)

Favorable attitude

Unfavorable attitude

\begin{tabular}{|c|c|c|c|c|c|}
\hline \multicolumn{2}{|c|}{ Disagree } & \multicolumn{2}{|c|}{ Not sure } & \multicolumn{2}{|c|}{ Agree } \\
\hline № & $\%$ & № & $\%$ & № & $\%$ \\
\hline 131 & 26.8 & 282 & 57.7 & 76 & 15.5 \\
\hline 96 & 19.6 & 161 & 33.0 & 232 & 47.4 \\
\hline 255 & 52.1 & 86 & 17.6 & 148 & 30.3 \\
\hline 72 & 14.7 & 164 & 33.6 & 253 & 51.7 \\
\hline 106 & 21.7 & 242 & 49.5 & 141 & 28.8 \\
\hline 84 & 17.2 & 273 & 55.9 & 132 & 26.9 \\
\hline 135 & 27.6 & 108 & 22.1 & 246 & 50.3 \\
\hline 101 & 20.7 & 226 & 46.2 & 162 & 33.1 \\
\hline \multicolumn{3}{|c|}{ № } & \multicolumn{3}{|c|}{$\%$} \\
\hline \multicolumn{3}{|c|}{229} & \multicolumn{3}{|c|}{46.8} \\
\hline \multicolumn{3}{|c|}{260} & \multicolumn{3}{|c|}{53.2} \\
\hline
\end{tabular}

Table 4: Attitude towards Emergency Contraception among Female Students, Mizan-Tepi University, south west Ethiopia, March, 2014 (n=489).

\section{Variables}

Used EC among those who had sex since in the campus $(n=188)$

Yes

No

Used EC among those who had unprotected sex $(n=123)$

Yes

No

Types of EC used $(n=68)$

ECPs

IUCD

\begin{tabular}{|c|c|}
\hline Number & Percent \\
\hline 68 & 36.2 \\
\hline 120 & 63.8 \\
\hline 57 & 46.3 \\
\hline 66 & 53.7 \\
\hline 66 & 97.1 \\
\hline 2 & 2.9 \\
\hline
\end{tabular}

Table 5: Emergency Contraception Utilization among Female Students of Mizan-Tepi University, south west Ethiopia, March, 2014.

studies conducted in higher institutes in Cameron Uganda, Nigeria and other developing countries reported similar findings [14,20,22].

Concerning the summary index of knowledge and attitude towards EC, the finding of the study shows that $24.1 \%$ and $46.8 \%$ of female students were found to have good knowledge and favorable attitude towards EC respectively. This finding is consistent with the studies conducted in Arbaminch and Jimma [10,11], but much lower than that of Cameroon and Nepal $[14,23]$. This difference might be attributed to the differences in provision of sexual and reproductive health education at schools \& higher learning institutions as well better practice of open and free discussion on sex and sexuality among female students in these countries. This finding reveals that comprehensive knowledge and attitude about EC methods is lacking among MTU female students.

With respect to the use of EC, among those who had ever sex since entered in the campus, only 68(36.2\%) had ever used EC and it was 57(46.3\%) among those who had unprotected sex, the discrepancy occurred because 11 students used EC while having protected sex and the possible explanations for this could be either they might prefer to use dual contraceptive method or might be due to missed pills of regular contraceptive (i.e. as backup method). This finding is inconsistent with the study conducted in Adama University [8]. The possible explanation for a higher EC practice observed in this study might be related to differences in the sample size between the two studies and increase in the level of awareness as the time of the study goes on might also be another possible explanation. In agreement with other studies findings, oral EC pill were the most widely known and used emergency contraception [24].

Higher education female students are exposed to many sexual and reproductive health problems among which unintended pregnancy is one of them, which could be prevented by early use of EC. However, as shown in this study, correct knowledge and utilization of EC among MTU female students is limited. As a limitation, this study cannot ascertain cause and effect relationship since it is a cross-sectional type, social desirability bias cannot be totally eliminated as the study touches sensitive issues that might lead to under reporting.

\section{Conclusions}

In conclusion, this study showed that, lack of adequate knowledge and, unfavorable attitude towards EC among most of the female students, despite high proportion of unprotected sex against pregnancy, the study also reviled lower utilization of EC. Therefore, based on the findings it is recommended that strategy and policy makers should develop appropriate evidence-based strategies and curricula in higher institutions to prevent unintended pregnancy and to promote the need based use of EC.

Thus, designing strategies towards awareness creation and attitude changing activities about EC through provision of different regular 
Citation: Shiferaw BZ, Gashaw BT, Tesso FY (2016) Knowledge, Attitude and Practice of Emergency Contraceptives among Mizan-Tepi University Female Students, South West Ethiopia. J Pain Manage Med 2: 111.

Page 6 of 7

\begin{tabular}{|c|c|c|c|c|}
\hline \multirow{2}{*}{ Variables } & \multicolumn{2}{|c|}{ Knowledge } & \multicolumn{2}{|l|}{ Attitude } \\
\hline & COR $(95 \% \mathrm{Cl})$ & AOR (95\% Cl) & COR $(95 \% \mathrm{Cl})$ & AOR $(95 \% \mathrm{Cl})$ \\
\hline \multicolumn{5}{|l|}{ Age } \\
\hline & $3.5(1.802,10.1)$ & $2.37(1.102,4.25)^{*}$ & $3.80(2.53,5.71)$ & $1.8(2.2,4.96)^{\star}$ \\
\hline $15-19$ years & 1.00 & 1.00 & 1.00 & 1.00 \\
\hline \multicolumn{5}{|l|}{ Residence } \\
\hline Urban & $1.4(1.10,2.01)$ & $1.3(0.98,1.70)$ & $081(.051, .129)$ & $0.42(0.16,1.51)$ \\
\hline Rural & 1.00 & 1.00 & 1.00 & 1.00 \\
\hline \multicolumn{5}{|l|}{ Year of study } \\
\hline Year II \& above & $3.55(1.95,6.46)$ & $2.4(1.12,3.83)^{*}$ & $3.25(1.33,7.97)$ & $3.15(0.94,10.49)$ \\
\hline Year I & 1.00 & 1.00 & 1.00 & 1.00 \\
\hline \multicolumn{5}{|l|}{ Marital status } \\
\hline Ever Married & $1.54(1.36,3.71)$ & $1.21(0.81,2.13)$ & $1.3(0.77,2.92)$ & $1.13(0.67,2.26)$ * \\
\hline Singles & 1.00 & 1.00 & 1.00 & 1.00 \\
\hline \multicolumn{5}{|l|}{ History of pregnancy } \\
\hline Yes & $9.93(5.80,17.01)$ & $4.45(6.00,9.88)^{*}$ & $4.60(2.59,8.17)$ & $3.52(2.03,7.97)^{*}$ \\
\hline No & 1.00 & 1.00 & 1.00 & 1.00 \\
\hline \multicolumn{5}{|l|}{ Ever use regular contraceptives } \\
\hline Yes & $10.66(6.18,18.39)$ & $5.01(5.23,14.27)^{\star *}$ & $8.16(4.7,20.67)$ & $4.5(0.89,12.82)$ \\
\hline No & 1.00 & 1.00 & 1.00 & 1.00 \\
\hline \multicolumn{5}{|l|}{ Sexual experience } \\
\hline Yes & $7.38(3.68,11.1)$ & $4.9(2.68,9.65)^{*}$ & $6.20(2.47,8.98) 4.81(3.80,7.45)^{*}$ & \\
\hline No & 1.00 & 1.00 & 1.00 & 1.00 \\
\hline
\end{tabular}

* P-value $<0.05$ and ** P-value $<0.001$

Table 6: Factors Associated with Knowledge $(n=332)$ and attitude $(n=489)$ of Emergency Contraception among Female Students, Mizan-Tepi University, south west Ethiopia, March, 2014.

\begin{tabular}{|c|c|c|c|c|}
\hline \multirow{3}{*}{ Variables } & \multicolumn{2}{|c|}{ Used EC } & \multicolumn{2}{|c|}{ Odds Ratio } \\
\hline & Yes & No & \multirow{2}{*}{ COR $(95 \% \mathrm{Cl})$} & \multirow{2}{*}{ AOR $(95 \% \mathrm{Cl})$} \\
\hline & N (\%) & N (\%) & & \\
\hline \multicolumn{5}{|l|}{ Age } \\
\hline$\geq 20$ years & $45(66.2 \%)$ & $61(50.8 \%)$ & $1.89(1.02,3.50)$ & $2.12(0.45,9.98)$ \\
\hline $15-19$ years & $23(33.8 \%)$ & $59(49.2 \%)$ & 1.00 & 1.00 \\
\hline \multicolumn{5}{|l|}{ Year of study } \\
\hline Year II \& above & $54(79.4 \%)$ & $77(64.2 \%)$ & $2.15(1.07,4.32)$ & $0.60(0.13,2.79)$ \\
\hline Year I & $14(20.6 \%)$ & $43(35.8 \%)$ & 1.00 & 1.00 \\
\hline \multicolumn{5}{|l|}{ Field of study } \\
\hline Health sciences & $21(30.9 \%)$ & $25(20.8 \%)$ & $1.69(.86,3.34)$ & $0.52(0.18,1.48)$ \\
\hline None Health sciences & $47(69.1 \%)$ & $95(79.2 \%)$ & 1.00 & 1.00 \\
\hline \multicolumn{5}{|l|}{ Marital status } \\
\hline Ever Married & $22(32.4 \%)$ & $10(8.3 \%)$ & $5.26(2.31,11.98)$ & $2.90(0.95,8.78)$ \\
\hline Singles & $46(67.6 \%)$ & $110(91.7 \%)$ & 1.00 & 1.00 \\
\hline \multicolumn{5}{|l|}{ Age at first sexual intercourse } \\
\hline$\geq 20$ years & $43(63.2 \%)$ & $23(19.2 \%)$ & $7.25(3.71,14.18)$ & $4.04(1.72,9.52)^{*}$ \\
\hline $15-19$ years & $25(36.8 \%)$ & $97(80.8 \%)$ & 1.00 & 1.00 \\
\hline \multicolumn{5}{|l|}{ History of pregnancy } \\
\hline Yes & $47(69.1 \%)$ & $34(28.3 \%)$ & $5.66(2.95,10.84)$ & $3.12(1.34,7.24)^{\star}$ \\
\hline No & $21(30.9 \%)$ & $86(71.7 \%)$ & 1.00 & 1.00 \\
\hline \multicolumn{5}{|l|}{ Ever use regular contraceptives } \\
\hline Yes & $46(67.6 \%)$ & $31(25.8 \%)$ & $6.00(3.12,11.52)$ & $5.01(2.23,11.27)^{\star *}$ \\
\hline No & $22(32.4 \%)$ & $89(74.2 \%)$ & 1.00 & 1.00 \\
\hline \multicolumn{5}{|l|}{ Knowledge on EC } \\
\hline Good knowledge & $53(77.9 \%)$ & $29(24.2 \%)$ & $11.08(5.45,22.53)$ & $3.24(1.32,7.98)^{\star}$ \\
\hline Poor knowledge & $15(22.1 \%)$ & $91(75.8 \%)$ & 1.00 & 1.00 \\
\hline \multicolumn{5}{|l|}{ Attitude towards EC } \\
\hline Favorable attitude & $51(75.0 \%)$ & $70(58.3 \%)$ & $2.14(1.11,4.13)$ & $1.95(0.80,4.75)$ \\
\hline Un Favorable attitude & $17(25.0 \%)$ & $50(41.7 \%)$ & 1.00 & 1.00 \\
\hline
\end{tabular}

*Indicates a P-value of $<0.05$ and ** Indicates a P-value of $<0.001$

Table 7: Factors Associated with Emergency Contraception Utilization among Female Students, Mizan-Tepi University, south west Ethiopia, March, 2014 (n=188) 
Citation: Shiferaw BZ, Gashaw BT, Tesso FY (2016) Knowledge, Attitude and Practice of Emergency Contraceptives among Mizan-Tepi University Female Students, South West Ethiopia. J Pain Manage Med 2: 111.

health information and communication programs is implicated. Working in collaboration with governmental and nongovernmental organizations whose focus is to address the need of reproductive health services, with particular emphasis to family planning/EC, is therefore recommended for increasing awareness, knowledge, and positive attitude, need based practice of emergency contraceptives and decrease barriers among respondents.

\section{Competing Interest}

The authors declare that they have no any financial or non-financial competing interests.

\section{Authors' Contribution}

BZ: The principal investigator designed the study, collect, analyses and interprets the data, and also drafted the manuscript. BT: Equally participated in conceptualization of the study, design, analyses and interpretation of results as well as drafting and review of the manuscript. FY: Participated in conceptualization and design of the study, drafting and critical reviewing the manuscript. All authors read and approved the final manuscript.

\section{Authors' Information}

BZ: Lecturer- College of Medicine and Health Sciences, Department of Nursing, Wolkite University, Wolkite, Ethiopia.

BT: Assistant Professor of Maternal and Reproductive Health - College of Public Health and Medical Sciences, Department of Nursing and Midwifery, Jimma university, Ethiopia

FY: Senior lecturer- College of Public Health and Medical Sciences, Department of Nursing and Midwifery, Jimma university, Ethiopia

\section{Acknowledgment}

We would like to thank Jimma University, College of Public Health \& Medical Sciences for funding this research project. Our gratitude goes to MTU, supervisors, data collectors, respondent who participated on this study. Finally we thank for language editing Mr. Mark Demos (American peas corps volunteer, in Ethiopia) and Mr. Sefu Bogale (English language teacher in Wolkite University, Ethiopia).

\section{References}

1. World Health Organization (WHO), United States Agency for International Development (USAID) (2006) Johns Hopkins university: Family Planning: a global handbook for providers. Wisconsin Med J 105: 40-44.

2. Mesce D (2005) Unsafe Abortion: Facts and Figures. (1stedn) DC: Population Reference Bureau: 5-9.

3. http://www.who.int/reproductivehealth/publications/unsafe_abortion/induced abortion 2012.pdf.

4. http://www.guttmacher.org/pubs/fb_IAW.pdf.

5. Central Statistical Agency, Ethiopia and ORC Macro (2011) Ethiopia Demographic and Health Survey (EDHS) 2011. Addis Ababa, Ethiopia and Calverton, Maryland, USA: Central Statistical Agency and ORC Macro.

6. Arinze-Onyia SU, Onwasigwe CN, Uzochukwu BSC, Nwobi EA, Ndu AC et al. (2010) The Effects of Health Education on Knowledge and Attitudes to Emergency Contraception by Female Students of a Tertiary Educational Institution in Enugu, South East Nigeria. Niger J Physiol Sci. 25: 165-167.

7. Tilahun D, Assefa T, Belachew T (2010) Knowledge, attitude and practice of emergency contraceptives among adama university female students. Ethiop J Health Sci 20: 195-202

8. Tilahun FD, Assefa T, Belachew T (2010) Predictors of emergency contraceptive use among regular female students at Adama University, Central Ethiopia.Pan Afr Med J 7: 16.

9. Worku A (2011) Knowledge, attitude and practice of emergency contraceptives among female college students in Arba Minch. Ethiop J Heal Dev 25: 176-183.

10. Tajure N (2010) Knowledge, Attitude and Practice of Emergency Contraception among Graduating Female Students of Jimma University, Southwest Ethiopia. Ethiop J Health Sci 20: 91-97.

11. Akani C, Enyindah C, Babatunde S (2008) Emergency contraception: knowledge and perception of female undergraduates in the niger delta of Nigeria.Ghana Med J 42: 68-70.

12. Appiah-Agyekum NN, Kayi EA1 (2013) Students' perceptions of contraceptives in university of ghana.J Family Reprod Health 7: 39-44.

13. Kongnyuy EJ, Ngassa P, Fomulu N, Wiysonge CS, Kouam L, et al. (2007) A survey of knowledge, attitudes and practice of emergency contraception among university students in Cameroon.BMC Emerg Med 7: 7 .

14. Hiwot A, Bosena $T$ (2009) Knowledge, attitudes, and practices towards emergency contraception among female Jimma University students, Jimma, Southwest Ethiopia. Ethiopian Journal of reproductive health 3: 37-43.

15. Dessalegn B (2006) Assessment of Knowledge, attitude and practices on emergency contraception among women seeking post abortion care in Addis Ababa, Ethiopia. Addis Ababa University Libraries Electronic Thesis and Dissertations: AAU-ETD, Faculty of medicine: Thesis-public health.

16. Mengistu S (2007) Assessment of level of awareness and utilization of emergency contraception among college female students in Oromia Regional State, Arsi Zone, Assella. Addis Ababa University Libraries Electronic Thesis and Dissertations: AAU-ETD, Faculty of medicine: Thesis-public health.

17. Gebrehiwot H, Gebrekidan B, Berhe H, Kidanu K (2012) Assessment of Knowledge, Attitude, and practice towards emergency contraceptives among female college students at mekelle town, tigray region, Ethiopia. Int J Pharm scinces research 4:1028-1035.

18. Manena-Netshikweta Ml (2007) Knowledge, perception and attitude regarding contraceptives among secondary school learners in the Limpopo province, South Africa.

19. Aziken ME, Okonta PI, Ande AB (2003) Knowledge and Perception of Emergency Contraception among Female Nigerian Undergraduates. Int Fam Plan Perspect 29: 84-87.

20. Wegene T, Fikre E (2005) Knowledge, attitude and practice on Emergency Contraceptives among female students at higher educations in Addis Ababa. Ethiop J Health Dev 21: 111-116.

21. Byamugisha JK (2007) User and provider perspectives emergency contraception among young people in Uganda, 2007, Kampala and Stockholm.

22. Adhikari R (2009) Factors affecting awareness of emergency contraception among college students in Kathmandu, Nepal.BMC Womens Health 9: 27.

23. Consortium on Reproductive Health Association (CORHA) (2005) Assessment of the reproductive health situations/ problems of students in the Addis Ababa, Bahirdar, Jimma, and Mekele Universities.

24. http://www.popcouncil.org/pdf/EcAfrique-3-1.pdf. 